Table 1. Mortality rates and incidence rate ratios

\begin{tabular}{|c|c|c|c|c|c|c|c|}
\hline & \multicolumn{3}{|c|}{ PsA cases } & \multicolumn{3}{|c|}{ Population controls } & \multirow[b]{2}{*}{$\begin{array}{c}\text { Incidence } \\
\text { rate ratio } \\
(95 \% \mathrm{Cl})\end{array}$} \\
\hline & $\begin{array}{c}\text { Number } \\
\text { of } \\
\text { deaths }\end{array}$ & $\begin{array}{c}\text { Person- } \\
\text { years } \\
\text { at risk }\end{array}$ & $\begin{array}{c}\text { Mortality } \\
\text { rate }^{\star}\end{array}$ & $\begin{array}{c}\text { Number } \\
\text { of } \\
\text { deaths }\end{array}$ & $\begin{array}{l}\text { Person- } \\
\text { years } \\
\text { at risk }\end{array}$ & $\begin{array}{c}\text { Mortality } \\
\text { rate* }\end{array}$ & \\
\hline Overall & 3121 & 268402 & 11.6 & 12884 & 1302250 & 9.9 & $\begin{array}{c}1.18 \\
(1.13-1.22)\end{array}$ \\
\hline Males & 1459 & 120517 & 12.1 & 6468 & 580285 & 11.1 & $\begin{array}{c}1.09 \\
(1.03-1.15)\end{array}$ \\
\hline Females & 1662 & 147886 & 11.2 & 6416 & 721966 & 8.9 & $\begin{array}{c}1.27 \\
(1.20-1.34)\end{array}$ \\
\hline $\begin{array}{l}\text { Longer disease } \\
\text { duration }\end{array}$ & 1943 & 139379 & 13.9 & 7459 & 670174 & 11.1 & $\begin{array}{c}1.25 \\
(1.19-1.32)\end{array}$ \\
\hline $\begin{array}{l}\text { Shorter disease } \\
\text { duration } \\
\text { Age intervals (y }\end{array}$ & 1178 & 129023 & 9.1 & 5425 & 632077 & 8.6 & $\begin{array}{c}1.06 \\
(1.00-1.13)\end{array}$ \\
\hline$<40$ & 18 & 33568 & 0.5 & 98 & 163278 & 0.6 & $\begin{array}{c}0.89 \\
(0.54-1.48)\end{array}$ \\
\hline $40-49$ & 90 & 50552 & 1.8 & 322 & 246955 & 1.3 & $\begin{array}{c}1.37 \\
(1.08-1.73)\end{array}$ \\
\hline $50-59$ & 280 & 65820 & 4.3 & 1131 & 321730 & 3.5 & $\begin{array}{c}1.21 \\
(1.06-1.38)\end{array}$ \\
\hline $60-69$ & 723 & 70224 & 10.3 & 3132 & 341587 & 9.2 & $\begin{array}{c}1.12 \\
(1.04-1.22)\end{array}$ \\
\hline $70-79$ & 960 & 37232 & 25.8 & 4160 & 178909 & 23.3 & $\begin{array}{c}1.11 \\
(1.03-1.19)\end{array}$ \\
\hline$\geq 80$ & 1050 & 11007 & 95.4 & 4041 & 49791 & 81.2 & $\begin{array}{c}1.18 \\
(1.10-1.26)\end{array}$ \\
\hline
\end{tabular}

* Per 1000 person-years.

Disclosure of Interests: Sofia Exarchou Consultant of: AbbVie, Novartis, Daniela Di Giuseppe: None declared, Gerd-Marie Alenius: None declared, Eva Klingberg Speakers bureau: Eli Lilly, Consultant of: Novartis, Grant/research support from: Roche, Valgerdur Sigurdardottir Consultant of: Novartis, Sanofi, Sara Wedrén: None declared, Ulf Lindström: None declared, Carl Turesson Speakers bureau: AbbVie, BMS, Pfizer, Roche, Consultant of: Roche, Grant/research support from: BMS, Lennart T.H. Jacobsson Consultant of: AbbVie, Eli Lilly, Janssen, Novartis, Pfizer, Johan Askling Grant/research support from: For ARTIS: AbbVie, BMS, Eli Lilly, Merck, Pfizer, Roche, Samsung Bioepis, Sanofi, UCB. This study was supported by AbbVie, Amgen, Eli Lilly, Novartis and Pfizer. The sponsors were allowed to comment on the study protocol and were provided with a report of the results, but had no influence on the study design or decision to submit the abstract., Johan K Wallman Consultant of: Celgene, Eli Lilly, Novartis DOI: 10.1136/annrheumdis-2021-eular.104

\section{OP0219 \\ THE ASSOCIATION OF PSORIATIC ARTHRITIS WITH ALL-CAUSE MORTALITY AND LEADING CAUSES OF DEATH IN PSORIATIC ARTHRITIS}

A. Haddad ${ }^{1}$, W. Saliba ${ }^{2,3}$, I. Lavi ${ }^{3}$, A. Batheesh ${ }^{4}$, S. Kasem ${ }^{2,4}$, T. Gazitt ${ }^{1}$, I. Feldhamer ${ }^{5}$, A. Cohen ${ }^{5,6}$, D. Zisman ${ }^{1,2}$. ${ }^{1}$ Carmel Medical Center, Rheumatology, Haifa, Israel; ${ }^{2}$ Technion, Ruth and Bruce Rappaport Faculty of Medicine, Haifa, Israel; ${ }^{3}$ Clalit Health Services, Department of Epidemiology, Haifa, Israel; ${ }^{4}$ Carmel Medical Center, Internal Medicine, Haifa, Israel; ${ }^{5} \mathrm{Clalit}$ Health Services, Department of Epidemiology, Telaviv, Israel; ${ }^{6}$ Ben Gurion University of the Negev, Dermatology, Bear-Sheva, Israel

Background: Data on the association between PsA and mortality remains conflicting as it has been hampered by small sample size with few events and the potential for confounders of selection and severity biases from clinic-based studies.

Objectives: To examine the association between PsA and all-cause mortality in a cohort of PsA patients and matched controls, using data from a population-based large medical record database.

Methods: Patients with newly diagnosis of PsA between January $1^{\text {st }}, 2003$ and December $31^{\text {st }}, 2018$ from the Clalit Health database were identified. 4 controls without PsA were selected and matched to cases of PsA by age (within 1 year), sex, ethnicity (Jewish vs. non-Jewish), and index date. The two groups were followed from the index date until the first occurrence of death from any cause or end of follow-up (June 30, 2019). Data on mortality and on the immediate cause of death was based on the Notification of Death form legally required by the Israeli Ministry of the Interior for every deceased person in the country. Demographic data including age, sex, ethnicity (Jewish or Arab), and socioeconomic status (SES) at inception were retrieved from the $\mathrm{CHS}$ database. Data regarding tobacco use (ever), obesity, body mass index, diabetes mellitus, hyperlipidemia, hypertension, ischemic heart disease, prior cerebrovascular accident, congestive heart failure, chronic renal failure, chronic obstructive pulmonary disease, cirrhosis, prior malignancy, psoriasis, and the concomitant use of glucocorticosteroids, conventional and biologic disease-modifying anti-rheumatic drugs (cDMARDs and bDMARDs, respectively) were extracted from the database.

We estimated the attributable fraction of the various causes of death in PsA patients and compared it to the proportionate mortality rate (PMR) of the leading causes of death in Israel during 2014-2016 based on a recently published report by the Central Bureau of Statistics. Cox proportional hazard regression models were used to estimate the crude and the multivariate adjusted hazard ratio (HR) for the association between PSA and all-cause mortality, as well as for factors associated with mortality within the PsA group.

Results: A total of 5275 PsA patients were identified between 2003 and 2018 and where matched to 21,011 controls based on age, sex, and ethnicity. The mean age was $51.7 \pm 15.4$ years of whom $53 \%$ were females. More individuals in the PsA group were smokers, obese, with diabetes, hypertension, and dyslipidemia, as well as with a history of ischemic heart disease, cerebrovascular disease, congestive heart failure, chronic obstructive pulmonary disease, chronic renal failure and cirrhosis than patients in the control group, and $38.2 \%$ of PsA patients were on b-DMARDS. Overall 471 (8.9\%) patients died in the PsA group compared to $1,668(7.9 \%)$ in the control group during a mean follow-up of $7.2 \pm$ 4.4 years. The crude HR for the association of PsA and all-cause mortality was $1.16(95 \% \mathrm{Cl}, 1.042-1.29)$. However, the association was not significant on multivariate analysis with $\mathrm{HR}$ of $1.096(95 \% \mathrm{Cl}, 0.977-1.229)$.

In PsA patients, malignancy was the leading cause of death, constituting $26 \%$ of all deaths, followed by ischemic heart disease $15.8 \%$, diabetes $6.2 \%$, cerebrovascular diseases $5.5 \%$ and septicemia $5.5 \%$, in keeping with the order of the leading causes of death in the general population of Israel during 2014-2016 as recently reported by the Central Bureau of Statistics.

On multivariate model Cox regression analysis, male sex, increased body mass index, increased Charlson comorbidity index scores and history of hospitalization in a year prior to death were associated with higher mortality, whereas treatment bDMARDs and cDMARDs were associated with a lower relative risk of death.

Conclusion: No clinically relevant increase in mortality rate was observed in PsA patients from the period 2003-2018. The most common causes of specific proportionate mortality rates in our cohort were similar to those in the general population.

Disclosure of Interests: None declared

DOI: 10.1136/annrheumdis-2021-eular.1895

\begin{tabular}{|l|l}
\hline OP0220 & SECULAR TRENDS IN BASELINE CHARACTERISTICS, \\
TREATMENT RETENTION AND RESPONSE RATES IN \\
17453 BIONAÏVE PSORIATIC ARTHRITIS PATIENTS \\
INITIATING TNFI - RESULTS FROM THE EUROSPA \\
COLLABORATION
\end{tabular}

S. N. Christiansen ${ }^{1}$, L. Midtbøll Ørnbjerg ${ }^{1}$, S. H. Rasmussen ${ }^{1}$, A. G. Loft ${ }^{2,3}$, J. K. Wallman ${ }^{4}$, F. lannone ${ }^{5}$, B. Michelsen ${ }^{1,6}$, M. J. Nissen ${ }^{7}$, J. Zavada ${ }^{8}$, M. J. Santos ${ }^{9}$, M. Pombo-Suarez ${ }^{10}$, K. Eklund ${ }^{11}$, M. Tomsic ${ }^{12}$, B. Gudbjornsson ${ }^{13}$, İ. Sari ${ }^{14}$, C. Codreanu ${ }^{15}$, D. DI Giuseppe ${ }^{16}$, B. Glintborg ${ }^{1,3}$, M. Sebastiani ${ }^{17}$, K. M. Fagerli ${ }^{6}$, B. Moeller ${ }^{18}$, K. Pavelka ${ }^{8}$, A. Barcelos ${ }^{19}$, C. Sánchez-Piedra ${ }^{20}$, H. Relas ${ }^{11}$, Z. Rotar $^{12}$, T. Love ${ }^{13}$, S. Akar ${ }^{21}$, R. lonescu ${ }^{15}$, G. Macfarlane ${ }^{22}$, M. G. H. Van de Sande ${ }^{23}$, M. L. Hetland ${ }^{1,3}$, M. Østergaard ${ }^{1} .{ }^{1}$ Rigshospitalet Glostrup, Copenhagen Center for Arthritis Research (COPECARE), Center for Rheumatology and Spine Diseases, Centre for Head and Orthopedics, Glostrup, Denmark; ${ }^{2}$ Aarhus University Hospital, Department of Rheumatology, Aarhus, Denmark; ${ }^{3}$ Rigshospitalet Glostrup, DANBIO Registry, Glostrup, Denmark; ${ }^{4}$ Skåne University Hospital, Lund University, Lund, Sweden; ${ }^{5}$ University of Bari, Rheumatology Unit, Bari, Italy; ${ }^{6}$ Diakonhjemmet Hospital, Division of Rheumatology, Oslo, Norway; ${ }^{7}$ Geneva University Hospital, Department of Rheumatology, Geneva, Switzerland; ${ }^{8}$ Institute of Rheumatology, Institute of Rheumatology, Prague, Czech Republic; ${ }^{9}$ Hospital Garcia de Orta, Rheumatology Department, Almada, Portugal; ${ }^{10} \mathrm{Hospital}$ Clinico Universitario, Rheumatology Service, Santiago de Compostela, Spain; ${ }^{11}$ Helsinki University Hospital, Department of Rheumatology, Helsinki, Finland; ${ }^{12}$ University Medical Centre Ljubljana, Department of Rheumatology, and Universitiy of Ljubljana, Faculty of Medicine, Ljubljana, Slovenia; ${ }^{13}$ Centre for Rheumatology Research, University Hospital and Faculty of Medicine, University of Iceland, Reykjavik, Iceland; ${ }^{14}$ Dokuz Eylul University School of Medicine, Division of Rheumatology, Izmir, Turkey; ${ }^{15}$ University of Medicine and Pharmacy, Carol Davila, Bucharest, Romania; ${ }^{16}$ Karolinska Institutet, Department of Medicine Solna, Stockholm, Sweden; ${ }^{17}$ University of Modena and Reggio Emilia, Rheumatology Unit, Modena, Italy; ${ }^{18}$ Inselspital, University Hospital Bern, Department Rheumatology \& Immunology, Bern, Switzerland; ${ }^{19}$ Centro Hospitalar do Baixo Vouga, Department of Rheumatology, Aveiro, Portugal; ${ }^{20}$ Sociedad Española de Reumatologia, Research Unit, Madrid, Spain; ${ }^{21}$ Katip Celebi University School of Medicine, Division of Rheumatology, Izmir, Turkey; ${ }^{22}$ University of Aberdeen, Aberdeen Centre for Arthritis and Musculoskeletal Health (Epidemiology Group), School of Medicine, Medical Sciences and Nutrition, Aberdeen, United Kingdom; ${ }^{23}$ Amsterdam Rheumatology and Immunology Center (ARC), Amsterdam UMC/AMC, University of Amsterdam, Amsterdam, Netherlands 